\title{
TERAPIA ATRAVÉS DA DANÇA COM LARINGECTOMIZADOS: RELATO DE EXPERIÊNCIA
}

Ana Carla Peto*

PETO, A.C. Terapia através da dança com laringectomizados: relato de experiência. Rev.latino-am.enfermagem. Ribeirão Preto, v. 8, n. 6, p. 35-39, dezembro 2000.

O presente relato descreve o primeiro encontro do laringectomizado com a Dança no Grupo de Apoio a Pessoa Ostomizada-Laringectomizados. Este estudo tem o objetivo de fornecer subsídios sobre a importância terapêutica e educativa da dança. A técnica utilizada foi uma dinâmica de grupo em roda com participação de vinte pacientes. A música e os movimentos corporais foram os recursos empregados para desenvolvermos a Terapia Através da Dança. Os resultados evidenciaram bom envolvimento dos pacientes na dinâmica através das linguagens verbal e não verbal e diminuição do estresse.

\section{UNITERMOS: terapia através da dança}

\section{INTRODUÇÃO}

A dança existe desde a pré história. Como os homens desta época não tinham uma linguagem verbal definida, usavam a dança e artefatos para se relacionarem e conviverem em sociedade. Era freqüente o uso desta arte para acalmar um deus irado ou fazer um ritual (ORDONES, 1990).

A dança é considerada, para todos os povos, em todos os tempos, um meio de comunicação e expressão. Este se materializa através dos movimentos dos corpos, organizados em seqüências significativas e de experiências que transcendem o poder das palavras e da mímica. É um modo de existir, pois representa a magia, religião, trabalho, festa, amor e morte. Os homens dançaram e continuam dançando em todos os momentos solenes de sua existência (GARAUDY, 1980).

Embora seja de costume dizer que o brasileiro tem samba no pé, que aqui já se nasce dançando, que o Brasil é um país que dança, através do carnaval, festa junina, trio elétrico, axé bahia, ainda há falta de conhecimento a respeito da Dança como instrumento de valor terapêutico e educativo. É de senso comum tentar encarar a dança como puro divertimento, desprovida de conteúdos e/ou de mensagens culturais que possam transformar a vida, e portanto, o convívio em sociedade.

A dança para a maioria, é sinônimo de código (ballet clássico, moderno, contemporâneo), de coreografia pronta ou de estilo musical (funk, rap, reggar, street dance) características atribuídas a dança que são cristalizadas pelas relações com a mídia. Para contrapor essa mensagem errônea, é necessário discutir e problematizar a necessidade de códigos externos, trabalhando com processos criativos em Dança. Estes permitirão ampliar o vocabulário de movimentos e torná-los um valioso instrumento para a comunicação e terapia.

A mistura entre razão e sensibilidade que o trabalho de Dança proporciona, através da terapia corporal do movimento, é essencial para atingir a compreensão dos processos intuitivos.

Essa linguagem não verbal contagia o corpo (que é o que vejo no outro e em mim) exterioriza a alma (é o que sinto, misturado com o que penso, imagino, quero, desejo, temo e mais coisas, todas elas fundamentalmente ligadas e dependentes do corpo). A dança dá sustentação, força e sentido aos pronunciamentos verbais e posições no espaço que o homem executa ao se relacionar com o grupo (GAIARSA,1995). Ela nasce da necessidade de comunicação com o transcendental, de conhecer o desconhecido, de estar em relação com o outro. É uma das raras atividades humanas em que o homem se encontra totalmente engajado - corpo, espírito e coração. É um meio de meditação e um esporte completo (GARAUDY, 1980).

A música também faz parte deste esporte lúdico, ela não se separa da dança, são interdependentes: desde a montagem dos Ballet de Repertório no século XVI as músicas foram feitas especialmente para as coreografias. Atualmente, esta continua sendo conseqüência da dança e recebem influências entre si para proporcionar saúde mental.

\footnotetext{
* Enfermeira, Pedagoga, Professora de Dança na Academia "Marilda Petto" e Membro do Garpo. Endereço: Rua: Acre, 320 Ipiranga - 14055-660 - Ribeirão Preto - São Paulo - Brasil
} 
Quando fazemos uma relação da linguagem musical com a linguagem corporal, vemos uma reação sobre a conduta do ser humano (MATEUS, 1997).

Ao atingir a maturidade musical e corporal, ministrando aulas de dança há doze anos, conclui que sempre amei o corpo humano. Na infância e adolescência trabalhei com ele através da emoção, arte e interpretação da vida através da Dança. Ao fazer Enfermagem e Pedagogia passei a enxergar o corpo de fora para dentro. Do mundo dos gestos, das expressões emocionais, do corpo sentido e as vezes sofrido, comecei a compreender o corpo através do estudo dos distúrbios viscerais de origem sócio-psicológica; a respiração como controle dos níveis de consciência para anatomia, fisiologia e bioquímica (GAIARSA, 1995).

Hoje, a interseção das três polaridades: Professora de Dança, Pedagoga e Enfermeira marcam profundamente minha existência, "banha" minha personalidade profissional e fortalece o pressuposto que a Dança, através da arte, leva a terapia e proporciona saúde ao indivíduo.

Desta forma acredito que a Dança possui valor terapêutico no Grupo de Apoio e Reabilitação da Pessoa Ostomizada - Laringectomizados - GARPO**

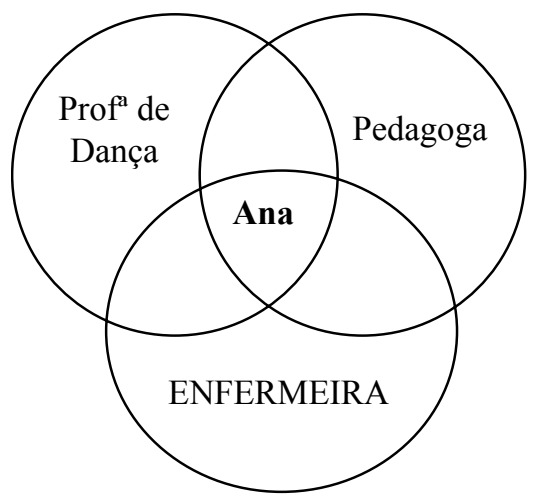

\section{O ENCONTRO: EU, A DANÇA E LARINGECTOMIZADOS.}

$O$ encontro com as peculiaridades de um laringectomizado ocorreu no $6^{\circ}$ Simpósio Brasileiro de Comunicação em Enfermagem quando presenciei uma apresentação de trabalho sobre o GARPO. O relato me incentivou a implementar um projeto de Dança, Alongamento e Expressão Corporal para o Grupo. Como professora de Dança, Educadora e Enfermeira tinha certeza de que a dança poderia auxiliá-los no conhecimento que envolve intuição, emoção, imaginação, capacidade de comunicação, uso da memória, interpretação, análise, síntese e avaliação crítica.

Com essas premissas inseri-me desde julho de 1.998 no GARPO.
Esse grupo se reúne todas as últimas quartas feiras do mês na Escola de Enfermagem de Ribeirão Preto e tem como objetivo a assistência, o ensino e a pesquisa sobre a reabilitação das pessoas laringectomizadas.

Desde então, a cada quinze dias, as quartas feiras, durante 30 minutos, realizo um projeto de Terapia Através da Dança com esses pacientes.

\section{OBJETIVOS}

O objetivo geral do trabalho é melhorar a qualidade de vida dos mesmos e conseqüentemente auxiliar no processo de reabilitação bio-psico-social.

Os objetivos específicos são:

- Apreciar e refletir sobre o gosto pela natureza e seu movimento para relacioná-lo ao movimento corporal;

- Liberar emoções para exteriorizar sentimentos através do verbal e não verbal;

- Transmitir os benefícios da terapia através da dança como exercício físico e lazer;

\section{METODOLOGIA}

Trata-se de um relato de experiência com pacientes laringectomizados que participaram do GARPO - laringectomizados, da Escola de Enfermagem de Ribeirão Preto. Utilizamos a técnica da dança, expressão corporal, alongamento e desenho através do lápis e papel.

A técnica foi aplicada na última quarta feira do mês de julho de 1998, participei de uma das reuniões do GARPO.

Para que os pacientes pudessem entender quem sou e meu trabalho, inicialmente forneci algumas explicações sobre os benefícios da Terapia Através da Dança e minha visão sobre o assunto.

\section{Pressupostos Teóricos:}

1 - Para me comunicar desde a infância usei, com grande freqüência a linguagem corporal da dança. Ela possibilita a compreensão dos movimentos corporais. Desperta o desejo de expressar e exprimir o mundo interior. Estabelece um novo código para exteriorizar novas experiências de vida, durante o desenvolvimento cognitivo. Iniciei este processo de análise com três anos de idade, fase em que já transmitia ao público as mensagens de histórias contadas pela linguagem corporal em diversas coreografias. 
2 - Existem outras formas de comunicação: Segundo ORDONES (1990) Dançar é conversar com Deus. Ao interpretar algumas coreografias na carreira de bailarina, tive possibilidade de estabelecer um paralelo com esta afirmação: percebia que minha comunicação com Deus se tornava completa. Hoje quando danço fico mais aberta para "insight" que ajudam a resolver os problemas.

3 - A postura tem tudo a ver com o modo dos seres humanos estarem no mundo e com suas atitudes psicológicas, de receber e selecionar estímulos, de avaliar e responder a situações. Alguns pacientes com câncer podem mostrar uma postura cabisbaixa e tristonha mesmo quando dizem estar bem. Para um bom leitor, essa resposta significa que o repertório verbal de alguns pacientes corre alto risco de dar uma imagem falsa, pouco ou nada ligada ao que eles efetivamente sentem ou pensam. Neste processo de diferença de resposta entre o que o corpo fala e o que a alma sente, são evidentes as divergências. É a alma vítima do corpo ou o corpo que assume o papel de vítima? Para equilibrar isso, a Terapia Através da Dança age reorganizando esta resposta (GAIARSA,1995).

4 - A Terapia Através da Dança é um exercício físico lúdico, que exerce um efeito de auto massagem em duplo sentido através de contrações musculares.

Os músculos não só renovam os próprios líquidos orgânicos como também, pelas suas variações de volume ao se contrairem, massageiam todos os tecidos próprios (GAIARSA, 1995).

Ativar a microcirculação do paciente laringectomizado é um elemento essencial para o programa de saúde, profilaxia e reabilitação, já que os males da vida sedentária (moléstias crônicas) podem ser evitados com movimentos corporais realizados no pós operatório.

A coordenação motora, trabalhada na dança, ativa três milhões de tirantes, cordéis ou puxões elementares, absorve dois terços dos neurônios cerebrais e estimulando o processo de raciocínio.

\section{DINÂMICA DE GRUPO}

Solicitei a permissão dos pacientes para realizar a dinâmica e divulgação dos resultados.

Ao iniciar a interação com os pacientes lembrei da frase os olhos são as janelas da alma. Quando os mesmos olharam para mim, senti através de seus olhos que irradiavam amor e empatia, que havia sido aceita pelo grupo e acolhida com muito carinho! Foi uma experiência única e contagiante..., a partir daí iniciei o trabalho.
Fizemos uma roda, pedi que dessem as mãos, com o objetivo de estabelecerem um contato significativo de aproximação, troca de energia, companheirismo e cinestésica. A idéia de dar as mãos, dançar em roda, equilibrar corpo e mente, leva ao trabalho de recuperação corporal.

Ao ouvirem o som da música com a luz apagada e olhos fechados, começaram a se movimentar espontaneamente de acordo com o ritmo.

É possível através da dança, interpretar ritmos internos não audíveis, que são descobertos dentro de cada ser humano e ritmos externos que são vistos ao nosso redor. A expressão do corpo e dos ritmos, que são produzidos de forma pessoal e grupal, podem fazer com que os enfermeiros consigam compreender o mundo desconhecido e valioso da linguagem não verbal da dança. O corpo, quando se expressa livremente através da dança, não pode mentir. O ritmo está em tudo na circulação na respiração... (FUX, 1988).

Há movimentos rítmicos em todo universo denominados dança cósmica de energia (CAPRA, 1995).

Ao terminar a música, pedi que levantassem as mãos (todos levantaram-nas sem soltar). Através deste gesto não verbal, procurei transmitir que seus pés estavam sob o chão - em metáfora ao processo de consciência, para resolver os problemas racionais; as mãos dadas significava que poderiam superar as dificuldades e desafios no pós operatório inicial.

Assim, através da "Dança da Vida" o mundo foi colocado no círculo e passado de mão em mão (ORDONES, 1990). Os movimentos expressões corporais e disposições dos indivíduos no espaço constituem-se de mensagens (SILVA, 1993).

Acendi as luzes, solicitei para que sentassem e escrevessem ou desenhassem os sentimentos e emoções presentes durante e após a dinâmica.

Ao observar os relatos lembrei da frase de Einsten: Por dolorosa experiência aprendemos que o pensamento racional não basta para resolver os problemas da vida social.

\section{RESULTADOS}

Os desenhos executados pelos laringectomizados no final da dinâmica de grupo demonstraram a existência de paz interior identificadas pelas figuras do sol, montanhas, passarinhos e flores.

Os relatos transmitiram que os clientes perceberam a existência de outras formas de comunicação, um paciente relatou: perdemos a voz, mas temos as pernas para andar, braços para abraçar, olhos para ver, ouvidos para ouvir, cabeça para pensar. 
Verifiquei que houve o desenvolvimento do pensamento artístico, gosto pela natureza, paz e liberação de sentimentos exteriorizando emoções, através do seguinte relato de um laringectomizado: transportei-me para um mundo repleto de flores e pássaros com uma harmonia de cantos simplesmente maravilhosa. As flores com um perfume tão envolvente que é totalmente impossível descrever. Emocionei-me!

A cooperação, respeito, diálogo e admiração construídos pelo grupo de apoio mostram-se evidentes no relato: veja ao seu redor quantas pessoas gostam de você ... seus pais, seus irmãos sua esposa e seus amigos. A vida continua; agradeço a Deus e aos amigos que encontrei aqui!.

Os relatos a seguir identificam promoção de saúde mental, presença de cultura religiosa, e aumento da auto estima entre os pacientes: a felicidade é como uma borboleta, que de repente pousa na vida da gente. Nunca devemos desanimar; Deus escreveu uma história de amor belíssima para cada um de nós.

Foi observado o gosto que os laringectomizados tem pela música instrumental: sempre gostei de música orquestrada. Se houvesse música nas conduções, no ambiente de trabalho, tudo seria melhor, os pensamentos mais nobres.

Ressalta-se ainda o entendimento quanto aos benefícios físicos promovidos pela dinâmica de Introdução a Terapia Através da Dança: adoro dançar...; adoro andar.....

Após a dinâmica de grupo, aproximou-se de mim um paciente e disse-me: quando eu era palhaço no circo dançava muito. Mostrou-me sapateando os pés e dizendo: você me faz lembrar os bons tempos.

Os resultados do trabalho de Introdução a Terapia Através da Dança foram ao encontro com a frase de GARAUDY (1980):

"A ação na dança, é a arte de fazer passar emoções e ações à alma do expectador pela expressão verdadeira de nossos movimentos, de nossos gestos e de nosso corpo".

\section{CONSIDERAÇÕES FINAIS}

A atividade desenvolvida proporcionou o estabelecimento de um progresso no desenvolvimento da comunicação verbal e não verbal entre os participantes. Possibilitou aumentar a interação entre grupo de apoio, pacientes e familiares.

A técnica auxiliou os pacientes a se tornarem conscientes das verdadeiras relações que há entre corpo, mente e emoção. $\mathrm{O}$ uso dos sentimentos, estimulados pela música, pelas mãos dadas e pelo balançar rítmicos dos corpos permitiram aflorar a percepção dos pacientes, sobre o processo de adaptação e recuperação no pós operatório.

Nos relatos foram expressados sentimentos positivos de carinho, paz, amizade, perseverança, minimizando bloqueios emocionais e facilitando a interação biopsicossocial do laringectomizado; melhorando assim o dialogo corporal, a saúde e aumentando a qualidade de vida destes pacientes.

\section{THERAPY THROUGH DANCE WITH LARINGECTOMIZED PATIENTS: THE DESCRIPTION OF AN EXPERIENCE}

This study describes the first contact of laringectomized people with dance in the Group of Support to OstomizedLaringectomized Patients. This study aimed at searching for elements about the therapeutic and educative importance of dance to them. The technique utilized was group dynamics with the participation of twenty patients. Music and body movements were resources employed for the development of therapy through dance. Results showed a good involvement of the patients in the dynamics though verbal and non-verbal language as well as a decrease in stress.

\section{KEY WORDS: therapy through dance, laringectomized}

\section{TERAPIA A TRAVÉS DE LA DANZA CON LARINGECTOMIZADOS: RELATO DE EXPERIENCIA}

El presente relato describe el primer contacto del laringectomizado con la danza en el Grupo de Apoyo a la PersonaOstomizada-Laringectomizado. Este estudio tiene el objetivo de ofrecer información sobre la importancia terapéutica y educativa de la danza. La técnica utilizada fue una dinámica de grupo con participación de veinte pacientes. La música y los movimientos corporales fueron los recursos usados para desenvolver la Terapia a través de la Danza. Los resultados mostraron buena participación de los pacientes en la dinámica a través del lenguaje verbal y no verbal, percibiéndose disminución del estrés. 


\section{REFERÊNCIAS BIBLIOGRÁFICAS}

01. CAPRA, F. O ponto de mutação. São Paulo: Cultrix, 1995.

02. FUX, M. Dançaterapia. São Paulo: Summus, 1988.

03. GAIARSA, J.A. O que é corpo. 7. ed. São Paulo: Brasiliense, 1995.

04. GARAUDY, R. Dançar a vida. 2. ed. Rio de Janeiro:

Nova Fronteira, 1980.
05. MATEUS, L.A.S. A música: elemento facilitador no relacionamento interpessoal enfermeiro cliente em sofrimento psíquico. Ribeirão Preto, 1997. 147p. Dissertação (Mestrado) - Escola de Enfermagem de Ribeirão Preto, Universidade de São Paulo.

06. ORDONES, R. Dançar é conversar com Deus. Ribeirão Preto: Academia Marilda Petto, 1990/ Mimeografado/.

07. SILVA, M.J.P. Construção e validação de um programa sobre comunicação não verbal para enfermeiros. São Paulo, 1993. 108p. Tese (Doutorado) - Escola de Enfermagem, Universidade de São Paulo. 